\title{
Comparison of Plain X-ray finding of Ventricular Enlargement with Echocardiography
}

\author{
Adhikary KP, Jha $\mathrm{S}^{2}$, Ghimire $\mathrm{RK}^{5}$, Pradhan $\mathrm{S}^{+}$
}

\begin{abstract}
Chest radiography is one of the first line investigations done to assess the cardiac size to rule out cardiomegaly. The present study was undertaken to compare the plain radiographic findings of ventricular enlargement with that of echocardiography.
\end{abstract}

39 patients with enlarged cardiac size based on cardio-thoracic ratio on chest X-ray underwent echocardiographic assessment. 29 male patients and 10 femalepatients were included In this study during a period of ten months in the year 2002. The median age was 51.0 years. Measurement of left ventricular enlargement based on the criterion developed by Devereux (1987) showed that $44.8 \%$ of males and $30.0 \%$ of females (total $41 \%$ ) had enlarged left ventricular mass per square meter of body surface who had enlarged cardiac shadows based on CT ratio measured on chest X-ray. According to the criterion set by American College of cardiology (1983) showed that only $51 \%$ of the total subjects who had enlarged cardiac size in chest radiography were found to have enlarged left ventricle. When compared with the Normogram values, end diastolic volume, end systolic volume and left ventricular posterior wall as diastole showed $15.4 \%, 28.3 \%, 43.6 \%$ and $23.0 \%$ of the total patients having enlarged left ventricle, who were having enlarged cardiac size based on the chest radiography. These values are statistically insignificant to prove the validity of CT ratio used to diagnose enlarged cardiac size. A maximum of $51.3 \%$ and a minimum of $15.4 \%$ (average $33.5 \%$ ) of the patients having enlarged cardiac size having no obvious radiographic markets on chest radiography of cardiac illness were proven to have cardiomegaly by various criteria using echocardiography. The left ventricular enlargement according to left ventricular mass by body surface area calculated by parameter specified by Devercux (1987) and American Collage of Cardiology (1983) had comparable values. Left ventricular size measured by systolic and diastolic volumes and wall thickness criteria had different values.

Key words: Ventricular enlargement, Echocardiography, CT ratio 


\section{Introduction}

The accurate measurement of heart size including ventricles is best made with crosssectional imaging, especially echocardiography and MRI, Methods for assessing the size of the ventricles, including ventricular enlargement, on the plain radiography are less accurate but are still useful and one of the basic investigations performed. The simple radiographic techniques used are the transverse cardiac diameter and the cardiothoracic ratio.

Ventricular enlargement is one of the commonly diagnosed findings in the department of radiology, Tribhuvan University Teaching Hospital (TUTH) amongst the patients undergoing plain chest radiography. It is commonly seen in patients presenting with symptoms of cardiac and respiratory system disease. The exact incidence of the disease in Nepal is not well known. However, by the number of cases diagnosed, it can be assumed that this is one of the common public health problems in our country having a rising trend.

Cardiomegaly, including ventricular enlargement, is one of the manifestations of the cardiovascular disease. The distribution of the disease is worldwide and is common amongst those having cardiomyopathy, valvular and congenital heart disease, heart failure, cor pulmonale, pulmonary hypertension, high cardiac output States and chronic pressure overload.

The diagnosis of cardiomegaly including ventricular enlargement depends upon imaging findings of plain chest $x$-ray and confirmed by the direct visitation of the heart chambers (echocardiography and $\mathrm{MRI}$ ). The diagnosis made by exclusively available plain $\mathrm{x}$-ray is varied therefore it is desirable to confirm the diagnosis by echocardiography, which is available in most of the specialist centers including TUTH.

This study was designed to compare the result of plain $x$-ray findings with the echocardiography findings. The study was conducted in the department of radiology and the department of medicine (cardiology). 


\section{Aim and objective of the study}

To find out the diagnostic accuracy of plain chest x-ray and compare it to the findings obtained on the same subjects on transthoracic echocardiography.

\section{Materials and Methods}

The study was a hospital based cross-sectional study. 39 cases referred to radiology department for chest x-ray and who were found to have enlarged cardiac size were selected on quota sampling basis and taken for echocardiography by the cardiologist.

\section{Study algorithm}

TUTH Out-patient / patient Departments

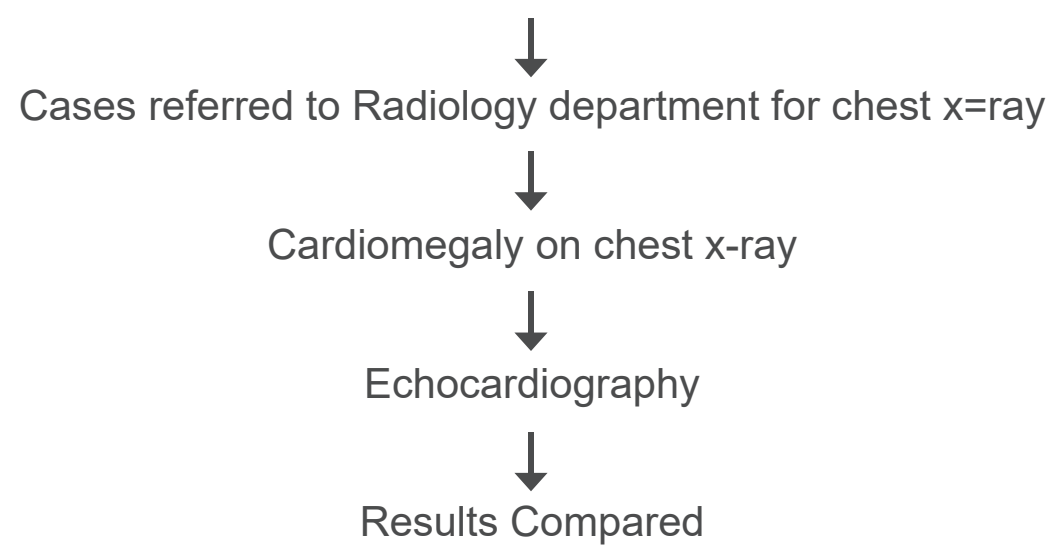

\section{Criteria of selection and exclusion of subject} Inclusion criteria

1. Patient attending the radiology department for plain chest radiography who are diagnosed as having enlarged ventricles.

2. Adult subjects of any age and sex.

\section{Exclusion criteria}

1. Patients with selective right atrial or left atrial enlargment.

2. Disputed plain radiography finding.

3. Patients with known cardiac disease.

\section{Methods of study}

The standard postero-anterior (PA)s projection ${ }^{2}$ of the chest was obtained with high kilovaltage (120-140 KVp) and high milliamperage (700 mA) technique at maximum inspiration to permit short exposure times, which stop cardiac motion, and sufficient 
penetration to visualise retrocardiac structures and pleural reflections. A tube-to-film distance of at least 6 feet was used to minimize distortion and magnification.

All echocardiography studies were performed using Hitachi Ultrasound Scanner EUB555 unit utilizing 2.5 and $5.0 \mathrm{MHz}, 2.5 \mathrm{em}$ diameter by one observer in the Department of cardiology, TUTH to avoid inter-observer bias.

The heart was imaged In a number of standard plans-long axis, short axis, and fourchamber planes. Likewise, the great vessels were transected in long and short axis with respect to the aorta to exclude the case in case there is any gross pathology in the great vessels.

After getting all the data the left ventricular mass was calculated using the formula ${ }^{5}$.

LV Mass=1.04 g/cc $\left[(D+I V S+P W)^{3}-D^{3}\right]-14 \mathrm{~g}$

Where, D means LV dimension, IVS means inter-ventricular septal dimension and PW means left ventricular posterior wall. All dimensions measured in $\mathrm{cm}$ at end diastole.

All the data were from primary source such as from plain PA chest radiography and echocardiography, All the data were evaluated by standard statistical methods. 
- NEPALESE HEART JOURNAL

\section{Observation and result}

Table No. 1

Left ventricular mass $/ \mathrm{m}^{2}$ body surface area ${ }^{6}$

(Values based on Devereux RB 1987)

\begin{tabular}{|c|c|c|c|}
\hline \multirow{2}{*}{ Sex } & \multicolumn{2}{|c|}{ Left ventricular mass } & \multirow{2}{*}{ Total } \\
\cline { 2 - 3 } & $<134 \mathrm{~g} / \mathrm{m}^{2}$ & $>134 \mathrm{~g} / \mathrm{m}^{2}$ & \\
\hline Male & $55.2 \%(\mathrm{n}=16)$ & $44.8 \%(\mathrm{n}=13)$ & $100 \%(\mathrm{nim}=29)$ \\
\hline
\end{tabular}

\begin{tabular}{|c|c|c|c|}
\hline \multirow{2}{*}{ Sex } & \multicolumn{2}{|c|}{ Left ventricular mass } & \multirow{2}{*}{ Total } \\
\cline { 2 - 3 } & $<100 \mathrm{~g} / \mathrm{m}^{2}$ & $>100 \mathrm{~g} / \mathrm{m}^{2}$ & \\
\hline Male & $70 \%(\mathrm{n}=7)$ & $30 \%(\mathrm{n}=3)$ & $100 \%(\mathrm{n}=10)$ \\
\hline Total & $59 \%(\mathrm{n}=23)$ & $41 \%(\mathrm{n}=6)$ & $100 \%(\mathrm{n}=39)$ \\
\hline
\end{tabular}

Using the values based on Devereux A B (1987) for left ventricular mass $/ \mathrm{m}^{2}$ body surgace area $44.8 \%$ of the males and $30 \%$ of the females had enlarged left ventricular mass. This added up to $41 \%$ of the total study population.

Table No. 2

Left ventricular mass based on Monogram values ${ }^{7}$

Werther J N, Singer S H, Kwan O H, et al 1983)

\begin{tabular}{|c|c|c|c|}
\hline \multirow{2}{*}{ Sex } & \multicolumn{2}{|c|}{ Left ventricular mass } & \multirow{2}{*}{ Total } \\
\hline & $<254 \mathrm{~g}$ & $>254 q$ & \\
\hline Male & $79.3 \%(n=23)$ & $20.7 \%(n=6)$ & $100 \%(n=29)$ \\
\hline Female & $100 \%(n=10)$ & $\mathrm{O} \%(\mathrm{n}=0)$ & $100 \%(n=10)$ \\
\hline Total & $84.6 \%(n=33)$ & $15.4 \%(n=6)$ & $100 \%(n=39)$ \\
\hline
\end{tabular}


Using the monogram values based on Werther J N, Singer SH, Kwan OH, et al (1983) for left ventricular mass, $20.7 \%$ of the males and $0 \%$ of the females had left ventricular mass more than 254 gram which is the upper limit of normal. The Population with enlarged left ventricular mass according to this monogram value was $15.4 \%$.

\section{Parameters based on American College of Cardiology (1983) ${ }^{8}$}

Table no. 3

End diastolic volume

\begin{tabular}{|c|c|c|c|}
\hline \multirow{2}{*}{ Sex } & \multicolumn{2}{|c|}{ EVD } & \multirow{2}{*}{ Total } \\
\cline { 2 - 3 } & $<90 \mathrm{mi} / \mathrm{m}^{2}$ & $>90 \mathrm{mi} / \mathrm{m}^{2}$ & \\
\hline Male & $75.8 \%(\mathrm{n}=22)$ & $24.2 \%(\mathrm{n}=7)$ & $100 \%(\mathrm{n}=29)$ \\
\hline Female & $60.0 \%(\mathrm{n}=6)$ & $40.0 \%(\mathrm{n}=4)$ & $100 \%(\mathrm{n}=10)$ \\
\hline Total & $71.7 \%(\mathrm{n}=28)$ & $28.3 \%(\mathrm{n}=11)$ & $100 \%(\mathrm{n}=39)$ \\
\hline
\end{tabular}

Parameters based on American College of Cardiology (1983), using the end diastolle volume to calculate the heart size it was found that $24.2 \%$ of the males and $40 \%$ of females had end diastolic volume in excess of $90 \mathrm{ml} / \mathrm{m}^{2}$, which was taken as the abnormal criterion. This corresponds to $28.3 \%$ of the study population.

Table No. 4

End systolic volume ${ }^{8}$

\begin{tabular}{|c|c|c|c|}
\hline \multirow{2}{*}{ Sex } & \multicolumn{2}{|c|}{ EVD } & \multirow{2}{*}{ Total } \\
\cline { 2 - 3 } & $<34 \mathrm{mI} / \mathrm{m}^{2}$ & $>34 \mathrm{mi} / \mathrm{m}^{2}$ & \\
\hline Male & $62.0 \%(\mathrm{n}=18)$ & $38.0 \%(\mathrm{n}=11)$ & $100 \%(\mathrm{n}=29)$ \\
\hline Female & $40.0 \%(\mathrm{n}=4)$ & $60.0 \%(\mathrm{n}=6)$ & $100 \%(\mathrm{n}=10)$ \\
\hline Total & $56.4 \%(\mathrm{n}=22)$ & $43.6 \%(\mathrm{n}=17)$ & $100 \%(\mathrm{n}=39)$ \\
\hline
\end{tabular}


Using the end systolic volume to calculate the heart size it was found that $38.0 \%$ of the males and $60 \%$ of females had end diastolic volume in excess of $34 \mathrm{ml} / \mathrm{m}^{2}$, which was taken as the abnormal criterion, This corresponds to $43.6 \%$ of the study population.

Table No.5

Left ventricular mass

\begin{tabular}{|c|c|c|c|}
\hline \multirow{2}{*}{ Sex } & \multicolumn{2}{|c|}{ EVD } & \multirow{2}{*}{ Total } \\
\cline { 2 - 3 } & $\geq 90 \mathbf{g} / \mathbf{m}^{2}$ & $>90 \mathbf{g} / \mathbf{m}^{2}$ & \\
\hline Male & $41.3 \%(n=12)$ & $68.7 \%(n=17)$ & $100 \%(n=29)$ \\
\hline Female & $70.0 \%(n=7)$ & $90,0 \%(n=3)$ & $100 \%(n=10)$ \\
\hline Total & $48.7 \%(n=19)$ & $51.3 \%(n=20)$ & $100 \%(n=39)$ \\
\hline
\end{tabular}

Using another parameter set by American College of Cardiology (1983), with the upper limit of left ventricular mass set at $90 \mathrm{~g} / \mathrm{m}^{2}$ it was found that $58.7 \%$ of the males and $30 \%$ of females had enlarged left ventricle which corresponds to $51.3 \%$ of the study population.

Table No.6

Left ventricular posterior wall at diastole ${ }^{8}$

\begin{tabular}{|c|c|c|c|}
\hline \multirow{2}{*}{ Sex } & \multicolumn{2}{|c|}{ PW } & \multirow{2}{*}{ Total } \\
\cline { 2 - 3 } & $\mathbf{< 1 2 . 9} \mathbf{~ m m}$ & $>\mathbf{1 2 . 9} \mathbf{~ m m}$ & \\
\hline Male & $51.3 \%(n=20)$ & $48.7 \%(n=9)$ & $100 \%(n=29)$ \\
\hline Female & $100 \%(n=10)$ & $0.0 \%(n=0)$ & $100 \%(n=10)$ \\
\hline Total & $77.0 \%(n=30)$ & $23.0 \%(n=9)$ & $100 \%(n=39)$ \\
\hline
\end{tabular}


Using the measurements of the left ventricular posterior wall at diastole it was seen that $48.7 \%$ of the males and $0.0 \%$ of females had end diastolic volume in excess of 12.9 $\mathrm{mm}$, which was taken as the abnormal criterion. This corresponds to $23.0 \%$ of the study population.

Bar diagram showing the number of patients with left ventricular enlargement compared with CT Ratio and LV mass index per sq. metre of body surface ${ }^{9}$

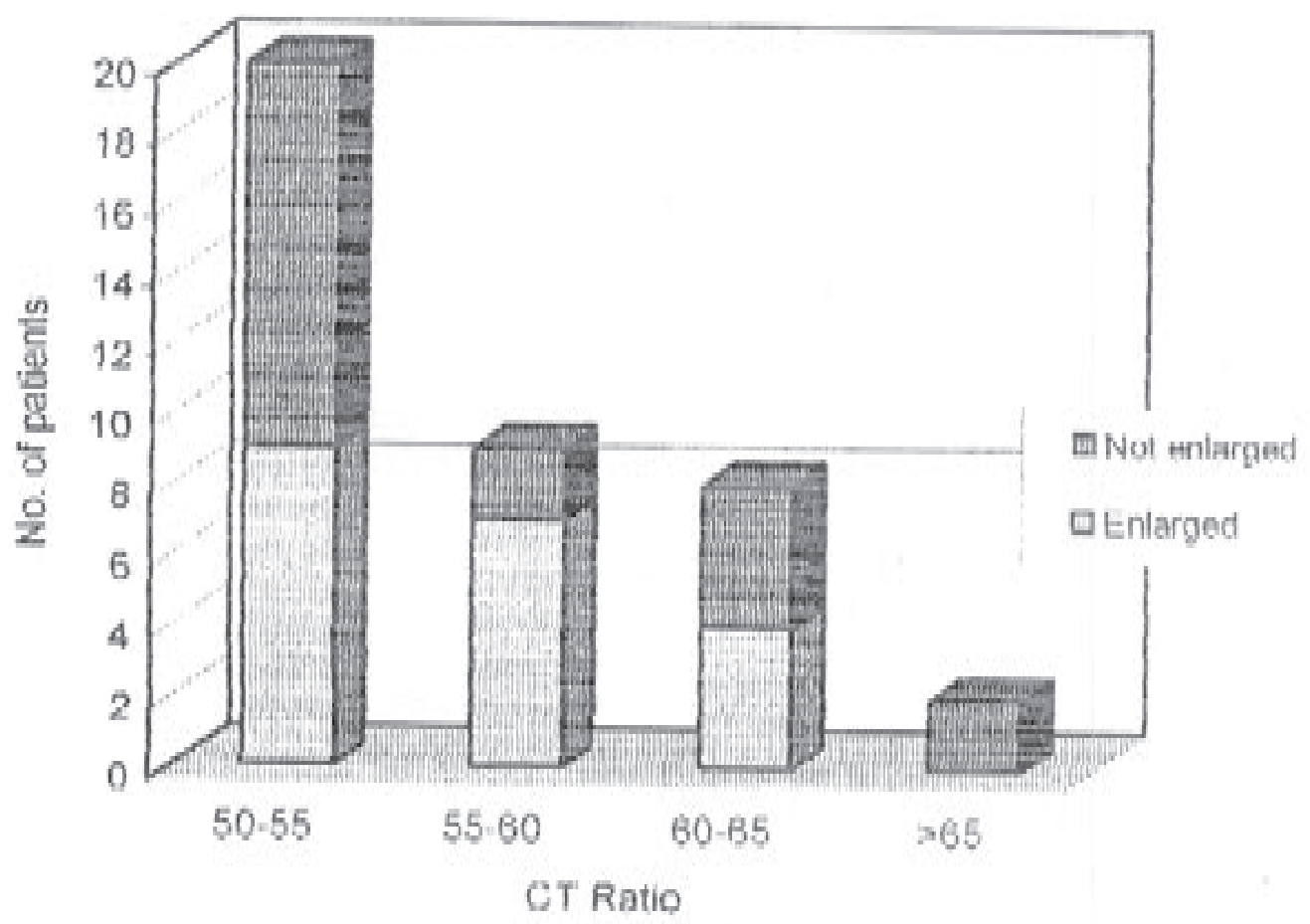

This figure shows the number of patients having left ventricular enlargement (LV mass Index $\left(>108 / \mathrm{m}^{2}\right.$ of body surface area) plotted against radiologically enlarged cardiac size (CT ration $>50$ ). Out of 20 patients in the category of $\mathrm{Ct}$ ration of $50-55$ nine $(45 \%)$ patients had enlarged cardiac size echocardiography. In the category 55-60, seven out of nine $(77 \%)$ had cardiomegaly. In the category $60-65$ CT ratio four out of eight $(50 \%)$ of the patients showed cardiomegaly. Of the total number of patients, twenty showed cardiomegaly echocardiography when this criterion ${ }^{79}$ was used. 


\section{Discussion}

Conventionally chest $x$-ray PA view was routinely done to assess the size of the heart taking cardiol-thoracic ratio as the standard measurement, but with the advent of newer technique, e.g., Echocardiography this study was conducted to test the reliability of chest $x$-ray in the diagnosis of cardiomegaly.

In this study, which comprised of 39 patients who had been reported as having enlarged cardiac size by chest radiography underwent echocardiography assessment. Different echocardiographic parameters of enlarged left ventricular mass were calculated based on Devercux (1987), Wyother (1983) and American College of Cardiology (1983). Some of the achocardiographic criteria developed by different authors and authorities had comparable findings, where as others differed. The following table illustrates the result.

Table No.7

Comparison of LV size by different measurement parameters

\begin{tabular}{|l|l|l|l|}
\hline \multirow{2}{*}{ Parameter } & \multicolumn{2}{|c|}{ Enlarged left ventricle } & \multirow{2}{*}{ Total } \\
\cline { 2 - 3 } & Male & Female & \\
\hline LV mass $/ \mathrm{m}^{2}$ & $44.8 \%$ & $30.0 \%$ & $41.0 \%$ \\
\hline LV mass $>90 \mathrm{~g} / \mathrm{m}^{2}$ & $58.7 \%$ & $30.0 \%$ & $51.3 \%$ \\
Monogram values & $20.7 \%$ & $0.0 \%$ & $15.4 \%$ \\
\hline End diastolic vol. & $24.2 \%$ & $40 \%$ & $28.3 \%$ \\
\hline End systolic vol. & $38.0 \%$ & $60 \%$ & $43.6 \%$ \\
\hline LV posterior wall & $48.7 \%$ & $0.0 \%$ & $23.0 \%$ \\
at diastole & & & \\
\hline
\end{tabular}


Measurement of left ventricular enlargement based on the criterion developed by Devereux (1987) showed that $44.8 \%$ of males and $30.0 \%$ of females (total $41 \%$ ) had enlarged left ventricular mass per square meter of body surface who had enlarged cardiac shadows based on CT ratio measured on chest x-ray.

Left ventricular enlargement using left ventricular mass per sq. meter (devereux, (1987) and left ventricular mass more than $90 \mathrm{~g}$ per sq. meter (Am Col card 1983) were comparable. According to the criterion set by American Collage of Cardiology (1983) showed that only $51 \%$ of the total subjects who had enlarged cardiac size in chest radiography were found to have enlarged left ventricle.

Similarly, when compared with the Monogram values ${ }^{10}$, end-diastolic volume, end systolic volume and left ventricular posterior wall as diastole showed $15.4 \%, 28.3 \%, 43.6 \%$ and $23.0 \%$ of the total patients having enlarged left ventricle, who were having enlarged cardiac size based on the chest radiography. These values are statistically insignificant to prove the validity of CT ratio used to diagnose enlarged cardiac size.

In this study a maximum of $51.3 \%$ and a minimum of $15.4 \%$ (average $33.35 \%$ ) of the patients having enlarged cardiac size having no obvious radiographic markers on chest radiography of cardiac illness were proven to have cardiomegaly by various criteria using echocardiography.

Out of 20 patients in the category of CT ratio of $50-55$, nine (45\%) patients had enlarged cardiac size echocardiographically. In the category $55-60$, seven out of nine $(77 \%)$ had cardiomegaly. In the category 60-65 CT raion four out of eight (50\%) of the patients showed cardiomegaly. Of the total number of patients twenty showed cardiomegaly echocardiographically when this criterion ${ }^{79}$ was used.

A cardiac size measurement by chest radiography is a relatively simple procedure with less inter-observer variability provided the technical factors governing the cruor are minimized and can therefore be used as screening tool, Chamber enlargement may be easy to diagnose by plain radiography when the chamber enlargement is gross, when it is contined to a single cardiac chamber, or when there is supporting evidence of abnormality from the aorta or pulmonary vessels, There are many facilities in the 
diagnosis of selective chamber enlargement produced either by chamber displacement mimicking enlargement, or by other structures that may resemble enlarged chambers. Additionally, apparent abnormalities of cardiac size and shape, resembling overall a selective chamber enlargement, may result from skeletal abnormalities, particularly of the sternum or dorsal spine. In practice these seldom affect management as chamber enlargement is confined and better assessed by cross-sectional imaging, usually by twodimensional echocardiography.

Chest radiography is not a sensitive method of detecting selective left ventricular enlargement, nor of recognizing it in the presence of enlargement of the other chambers. Echocardiography, CT and MRI allow much more precise assessment of chamber size.

Echocardiography being a very safe and easy to operate investigative tool can be used both in pregnant and non-pregnant females and is devoid of any radiation hazards and can be repeated on a person without risking him/her for the known side effects of x-rays. With the availability of simple, user-friendly portable and cheaper echocardiography machines it can be used as a more accurate, reliable, economic and scientific tool for assessment of therapy, screening and research purposes and many other wider applications.

Full dependence on chest radiography only to assess and diagnose the cardiac size may result into incomplete and inaccurate information to be required for the management of the patient.

Hence, it is advisable to conduct echocardiography on all cases of cardiomegaly that is diagnosed by chest $x$-ray irrespective of the clinical findings. 


\section{Conclusion}

In most adult patients with acquired heart disease, the disease process, although beginning on the left side of the heart, will eventually involve the pulmonary circulation and the right heart chambers, leading to gross cardiac enlargement. When this occurs, all the cardiac chambers are likely to be involved, and it is not possible to determine the contribution of each chamber with plain radiography, other than possibly the left atrium. The heart with all chambers enlarged takes on a globular shape, which is readily seen by plain chest radiography.

Chamber enlargement may be easy to diagnose by plain radiography when the chamber enlargement is gross, when it is confined to a single cardiac chamber, or when there is supporting evidence of abnormality from the aorta or pulmonary vessels. There are many facilities in the diagnosis of selective chamber enlargement produced either by chamber displacement mimicking enlargement, or by other structures that may resemble enlarged chambers. Additionally, apparent abnormalities of cardiac size and shape, resembling overall a selective chamber enlargement, may result from skeletal abnormalities, particularly of the sternum or dorsal spine. In practice these seldom affect management as chamber enlargement is confined and better assessed by cross-sectional imaging, usually by two-dimensional echocardiography,

\section{Biblography}

1. Eugene Braunwald 1990 Cardic Imaging: Clinical aspects of chest gerontology, WB Saunders, Philadelphia, pp 93

2. Bushong S C (ed) Merrill's Radiographic Positions and Radiologic Procedures, Mosby. Pp 1:5

3. Seward J B, Tajik a J, Edwards W D, Hagler D J 1987 Two-dimensional echocardiography atlas, vol 1 congenital heart disease Springer, New York

4. Grainger G, Allison D 2001 Grainger \& Allison's Diagnostic Radiology, Churchill Livingstonem China pp 699

5. Devereux R B and Reichek N 1977 Echocardiographic determination of left ventricular mass in man, Anatomic validation of the method; Circulation 55:613 
6. Devereux R B 1987 Detection of left ventricular hypertrophy by M-mode echocardiography: Anatomic validation, standardization and comparison to other methods. Hypertansion 9:11

7. WoythalerJ N, Singer SL, Kwan OL et al 1983 Accuracy of echocardiography versus électrocardiography in detecing left ventricular hypertrophy. Comparison with post-mortem mass measurements. J. Am. Coll, Cardiol 2:305

8. Maddahi J, Crucs J, Berman D S et al 1987 Non-invasive quantification of left ventricular myocardial mass by gated proton nuclear magnetic resonance imaging Journal of American College of Cardiology 10:682-692

9. Eugene Braunwald et al 1991 Cardiac Imaging: a companion to Braunwald's Heart disease. W B Saunders Company pp 134

10. WoythalerJ N, Singer S L, Kwan OL et al 1983 Accuracy of echocardiography versus electrocardiography in detecting left ventricular hypertrophy: Comparison with post-mortem mass measurements. J. Am. Coll, Cardiol 2:305

Dr. krishna P Adhikary, MD Resident, Department of Radiology, TUTH \# Dr, Sunil jha, MD, Associate Prof, Department of Medicine, TUTH \$ Dr, Ram K Ghimire, MD, Lecturer, Department of Radiology, TUTH + Dr, Sunil Pradhan, MD, Head, Department of Radiology, TUTH 